\title{
A crítica de arte e a arte como crítica: O legado de André Malraux
}

\author{
Art criticism and art as social criticism: \\ The legacy of André Malraux
}

Christine Ferreira AZZI

Instituto Brasileiro de Museus/Ministério da Cultura (IBRAM/MinC)

RESUMO: O artigo põe em cena a trajetória e o pensamento de André Malraux no âmbito das artes, da cultura e da estética. Malraux, como intelectual do século XX, se dedicou a diversas áreas de ação e de reflexão, tais como a crítica de arte, a história da arte, a política cultural, os museus, a literatura e o patrimônio. No presente estudo, procura-se traçar historicamente os caminhos da crítica de arte, assim como pôr as ideias malrucianas sobre arte e cultura em diálogo com as de outros pensadores, como Walter Benjamin e Michel Déguy.

PALAVRAS-CHAVE: André Malraux. Crítica de arte. Política cultural.

ABSTRACT: The paper presents the trajectory and thought of Andre Malraux in the arts, culture and aesthetics. Malraux, as a scholar of the twentieth century, is dedicated to various areas of action and reflection, such as art criticism, art history, cultural politics, museums, literature and heritage. The present study seeks to trace the paths of historical art criticism, as well as put malrucians ideas about art and culture in dialogue with other theorists as Walter Benjamin and Michel Déguy.

KEYWORDS: André Malraux. Art criticism. Cultural policy.

Esse artigo procura pôr em cena o legado crítico de André Malraux, escritor e crítico de arte na França do século XX, relacionado à arte e à cultura. Para tanto, procura-se analisar sua reflexão sobre o tema, presente em sua obra crítica sobre arte e seus discursos políticos, bem como apresentar um traçado histórico da crítica de arte como gênero e o cenário intelectual 
francês da época, a fim de compreender as circunstâncias que precederam o desenvolvimento das ideias malrucianas. Assim, ao investigar a vida e a obra intelectual de André Malraux, percebese que seu legado mostra um homem que foi além de seu tempo. Malraux criou uma expressiva obra literária e estética na qual problematiza a relação entre arte, cultura e humanidade, mas estendeu sua posição crítica a outros domínios, notadamente nos papéis de defensor de causas anticolonialistas, de combatente na resistência francesa e, ainda, de Ministro da Cultura da França entre 1959 e 1969. Questionado por fazer parte do governo De Gaulle, paradoxalmente Malraux é evocado na atualidade por militantes políticos que retomam seu nome como representativo de uma política cultural combatente e democrática ${ }^{1}$.

Pode-se afirmar que, oficialmente, seu trabalho na política tem início em 1958 quando é nomeado Ministro do Conselho pelo General Charles De Gaulle, cargo que ocupa por breve período. Em seguida, no ano de 1959, André Malraux torna-se Ministro da Cultura, com a criação do até então inexistente Ministério da Cultura. Deve-se ressaltar o fato de que a criação de uma política cultural na França tem lugar com o Ministério da Cultura. Sua ideologia se apóia em duas ações centrais: democratização e descentralização da cultura.

Até a saída do posto em 1969, com o desgaste do poder gaullista, as ideias que nortearam sua política foram pautadas em conceitos que há muito faziam parte de seu trabalho intelectual. Democratização, difusão e descentralização: para o homem que sempre buscara somar a luta e o combate ao pensamento, estava ali a oportunidade de pôr em ação suas reflexões sobre a importância do patrimônio, dos museus e da difusão da cultura. Em 1996, suas cinzas são transferidas ao Panteão de Paris, local no qual são enterradas as personalidades notáveis da França, com discurso do então Presidente Jacques Chirac. Mas seu legado intelectual

${ }^{1} \mathrm{O}$ evento ocorreu por ocasião do Colloque Culture, Politique et Politiques Culturelles: 50 ans du Ministère de la Culture, 1959 -2009, realizado no Teatro Nacional do Opéra Comique, Paris, em outubro de 2009. 
de forma alguma foi enterrado e se mostra até a atualidade como referência nos estudos sobre a interação entre arte, literatura e cultura.

\section{Fundamentos históricos da crítica de arte}

Para Michel Déguy, no artigo Du culturel dans l'art (2000), na dimensão política da arte o artista e o chefe de gabinete possuem em comum a atuação na esfera da cultura, campo em que estética e economia política são passíveis de serem unidas: "O artista e o chefe de gabinete têm um terreno em comum: o cultural. As esferas da estética e da economia política se entrelaçam, se recortam, se individualizam. O campo dessa confusão é o do cultural, para onde toda realidade é transferida" (DÉGUY, 2000, p.137).

Dessa forma, em sua perspectiva crítica, o que Déguy chama de o cultural configura uma zona de interseção entre campos de conhecimento - ainda que a priori pareçam áreas conflitantes - como arte, economia, política e filosofia. Nesse sentido, podese afirmar que André Malraux representa um homem cultural, na medida em que atua simultaneamente na esfera de artista, de administrador, de político e de crítico de arte. É justamente este último campo de ação que nos interessa particularmente, visto que ele em si parece condensar as outras áreas nas quais Malraux atua. A questão é que a essência do trabalho malruciano pode ser traduzida da seguinte maneira: sua obra encerra a função crítica da arte; isto é, a arte e a cultura como formas de interrogar o mundo.

A reflexão sobre arte se inicia através de uma vertente da filosofia que tem a arte como objeto: a estética. Marc Jimenez observa que o termo 'estética' é utilizado pela primeira vez na obra de Baumgarten, Aesthetica (1750). A partir daí o termo é difundido e adotado pelos filósofos do século XVIII: Kant o utiliza como subtítulo na obra "Crítica da faculdade de julgar" (1791); Schiller em "Cartas sobre a educação estética do homem (1795)"; Richter elabora "Curso preparatório de estética" (1804) e Hegel 
adota o termo (Lições de estética) em suas aulas (JIMENEZ, 1997, p.18).

A criação de uma nova disciplina no século XVIII que tem a arte como objeto constitui um evento significativo na história do pensamento ocidental, permitindo que se comece a pensar a distinção entre diversos domínios que tinham a arte ou o artista como objeto:

A fundação de uma nova disciplina constitui, no século XVIII, um grande acontecimento na história do pensamento ocidental. Não somente ela contribui à unificação do saber aspirada por Descartes no século anterior, como também ela permite a distinção entre domínios até então indistintos, que ainda hoje são confundidos (JIMENEZ, 1997, 21).

Este é o caso, por exemplo, da história da arte - surgida com a obra "História da arte antiga", de Winckelmann (1763) que compreende o estudo das obras, escolas e estilos no tempo e no espaço; e da teoria da arte, que pode ser definida como a reflexão que determinados artistas fazem de sua própria obra ou de sua época, a exemplo da Poética de Aristóteles, do "Tratado de pintura de Leonardo da Vinci", e da "Arte poética", de Boileau.

Assim, no século XVIII a estética se define como disciplina nova e autônoma, enquanto ciência, o que significa que a partir de então os filósofos, os artistas, os amantes da arte, os árbitros das artes (como então eram chamados os críticos de arte), o público cultivado dos salões, todos eles passam a dispor de um sistema de referências composto por normas, conceitos e noções. O que é mais importante ressaltar é que "[...] a fundação da estética como disciplina significa que o domínio da sensibilidade se torna objeto de reflexão" (JIMENEZ, 1997, p.25). Assim, a ideia mesma de estética no sentido moderno surge no momento em que a arte se reconhece e é reconhecida como atividade intelectual, perdendo sua acepção relacionada às atividades puramente manuais, como era no século XV. O século XVIII, portanto, permite a afirmação de ideias que evocam as transformações sociais de determinadas categorias no período, como os artistas, os aristocratas e a 
monarquia. É nesse sentido que se insurge, também, a reflexão acerca dos bens patrimoniais, ainda que sua concepção remetesse, na época, aos monumentos históricos e aos bens de valor artístico e financeiro, como observa Dominique Poulot (2003, p.37) no ensaio "Museu, nação, acervo".

Assim, verifica-se um crescente interesse, sobretudo a partir do século XVIII, no que se refere a uma reflexão sobre a obra de arte, o artista, o patrimônio e, de uma maneira mais ampla, à relação que se estabelece entre o artista e sua forma de ver o mundo. O olhar de fora que toma a arte como objeto fornece campo também para o surgimento da crítica de arte como exercício do olhar. A formação da crítica como campo de estudo também tem origem oficialmente no século XVIII, ainda que ela seja vista na dimensão de um "julgamento do belo". Jimenez (1997) lembra que, segundo Hegel, os ingleses classificavam a estética e a teoria da arte no domínio da crítica (critic), mostrando que as fronteiras entre os campos de estudo relacionados à arte ainda eram fluidas.

Para Jimenez (1997), a crítica se destaca como um método de reflexão filosófica, não sendo, necessariamente, um campo de especialistas, mas aberto a todos que desejem exercitar o debate sobre o conhecimento e a sabedoria.

Conforme Jimenez nos aponta, o escritor Denis Diderot, que teve papel significativo na difusão da crítica de arte como domínio, também compreendia o termo no sentido original grego, isto é, a crítica como exercício de direito do povo, garantia democrática de se expressar livremente (JIMENEZ, 1997, p.115). Em 1759, ele redige seu primeiro Salon, que será seguido de mais oito, configurando uma série de comentários acerca dos Salons organizados pela Academia Francesa de pintura e escultura. Os Salons eram exposições públicas que tinham como objetivo apresentar a obra dos membros da Academia Real, configurando um espaço no qual se observa o surgimento de discursos com julgamento de valor em relação à arte, como define Annie Becq (2002, p.91) no artigo Le XVIIIe siècle a-t-il inventé la critique d'art? . 
Precursor de um novo gênero, Diderot inaugura a crítica de arte moderna. De acordo com Jimenez, a posteridade vê em Diderot o fundador de um gênero literário novo, a crítica de arte sob sua forma moderna. Assim, a função da crítica de arte se afirma como espaço livre para discussão nas diversas instâncias da arte; discussão esta da qual a estética muito se beneficia (JIMENEZ, 1997, p.115).

No século XIX, os Salons se difundem, os progressos das técnicas de impressão permitem o desenvolvimento de jornais e revistas ilustrados, como a revista L'Artiste (1831), que republica textos de Diderot. A arte é posta em questão, assim como a estética e a crítica, excessivamente acadêmicas. A modernidade é inaugurada com a metamorfose de pensamento acerca de campos de conhecimento como a literatura, a filosofia e as artes. Michelet afirma em 1860: "Não criamos mais, a história matou a arte" (MICHELET apud JIMENEZ, 1997, p.303). Baudelaire (2007 apud JIMENEZ, 1997, p. 307) não apenas o contradiz, como define a modernidade "como anunciadora de mudanças mais profundas do que as precedentes". Baudelaire se consolida como crítico de arte ao redigir longos estudos sobre os Salons de 1845, de 1846 e de 1859; a Exposição Universal de 1855; bem como a obra "O pintor da vida moderna", de 1863. Para Baudelaire (2007), a modernidade existe em cada época e configura o elemento transitório e efêmero da obra de arte, suscetível às metamorfoses do tempo e do olhar que interferem na percepção da experiência estética:

A Modernidade é o transitório, o efêmero, o contingente, é a metade da arte, sendo a outra metade o eterno e o imutável. Houve uma modernidade para cada pintor antigo: a maior parte dos belos retratos que nos provêm das épocas passadas está revestida de costumes da própria época. [...] Não temos o direito de desprezar ou de prescindir desse elemento transitório, fugidio, cujas metamorfoses são tão freqüentes. Suprimindo-os, caímos forçosamente no vazio de uma beleza abstrata e indefinível, como a da única mulher antes do primeiro pecado. (BAUDELAIRE, 2007, p.26). 
Quanto às exposições universais, elas representavam espaços significativos de exibição de obras de arte que, impulsionadas pela industrialização, pela burguesia e pelo desenvolvimento tecnológico, se mostravam como uma vitrine do poderio econômico e social de cada nação. Por isso a predominância de países ocidentais (Portugal, Inglaterra, França) como sede desses eventos.

Marcadores da transição do século XIX para o XX, as exposições universais abrem caminho para os movimentos vanguardistas do início do século. A crítica de arte e a filosofia, afetadas pela angústia e pelo declínio da civilização e dos valores tradicionais, se voltam para uma vertente em que estética e política se vinculam. Pensadores como Georg Lukacs, Walter Benjamin, Herbert Marcuse e Theodor Adorno traduzem essa crise de valores que se reflete na arte e na reflexão sobre ela. Assim, consolidando um debate que permanece até a atualidade, a crítica de arte se coloca diante de um confronto: ou se vê a arte moderna e a metamorfose das formas tradicionais como meio privilegiado de expressão dessa crise de valores, ou como reflexo da própria decadência da sociedade industrial e pós-industrial (JIMENEZ, 1997, p.335).

É nesse contexto de crise de valores que se insere e se desenvolve, ao longo do século XX, o pensamento de Malraux, que se consolida no legado de escritores cuja reflexão fundamenta o conjunto de sua obra e de suas ações; colocando, sobretudo, a função crítica da arte como forma possível de mediação - e de compreensão - entre o sensível e inteligível, entre o homem e o destino.

Walter Benjamin (2001), na obra Le concept de critique esthétique dans le romantisme allemand, afirma que a teoria romântica da crítica estética foi elaborada principalmente por Friedrich Schlegel, e que toda crítica inclui o conhecimento de seu objeto. Para os teóricos do romantismo alemão, o conceito de crítica se desenvolveu em torno da relação entre reflexão e objeto, compreendendo este como médium-da-reflexão (médium-de-la- 
réflexion).A tarefa da crítica seria, portanto, acessaro conhecimento objetivo que emana desse objeto (arte). Conseqüentemente, a crítica consiste numa espécie de experimentação feita sobre a obra de arte, capaz de despertar a reflexão, o conhecimento e a consciência. Para Benjamin, a função da crítica estética é descobrir as disposições escondidas e as intenções secretas da obra de arte, considerando-a como objeto passível de reflexões infinitas. Assim, a crítica deve, em sua reflexão, ir além da obra de arte, ultrapassando-a e tornando-a absoluta, para que ela não seja mais incompleta. Segundo os românticos, então, a crítica não é um julgamento ou uma opinião sobre a obra, mas uma forma de concluí-la. Uma questão interessante colocada por Benjamin é o princípio da impossibilidade de criticar algo ruim, que determina que o silêncio ou o elogio irônico devam ser as formas de refutação indireta do que não merece ser criticado. A partir desse princípio, é possível compreender que a dimensão da crítica se refere à arte, como objeto mediador da reflexão, no que ela apresenta de positivo, não podendo, portanto, atingir a arte que não apresenta valorização estética ${ }^{2}$. Em suma, a crítica de arte não é um julgamento ou uma opinião sobre a obra, mas sobretudo uma formação, que vem à tona a partir da obra de arte, mas que, ao mesmo tempo, é independente desta. Assim, para Benjamin, a crítica propõe um desdobramento da obra de arte através da reflexão, e é nesse sentido que se pode compreender a obra malruciana como uma obra crítica sobre arte, em seu significado mais amplo.

Embora Malraux, no conjunto de sua obra, não aborde a questão da crítica propriamente dita, seu trabalho se apóia na reflexão sobre a arte, enxergando a obra justamente como um mediador da relação entre homem e arte, num diálogo construído através da reflexão e permeado por conceitos normalmente investigados pela crítica tradicional, como a história da arte, a

\footnotetext{
${ }^{2}$ Benjamin utiliza a expressão «valorização positiva» para se referir ao caráter qualitativo da obra de arte (BENJAMIN, Walter. Le concept de critique esthétique dans le romantisme allemand. 2001, p.161).
} 
forma e a beleza. Nos discursos, a reflexão estética se mostra central, ainda que o escritor valorize sobretudo uma problemática da arte, enfatizando a necessidade do trabalho de investigação da obra, em vez de expor uma linearidade de sua construção como objeto de estudo. Nesse aspecto ele vai ao encontro de Schlegel, que recusava qualquer pedagogismo na crítica de arte. Se a preleção malruciana pode ser pensada como crítica é sobretudo graças a seu caráter investigativo, que toma a obra de arte como processo de ressignificações infinitas, a que Malraux se refere como metamorfose da arte, conceito que será estudado mais adiante. Se a história da arte está presente em seus discursos, ela se mostra muito mais como elemento de costura entre os conceitos apresentados e o tema em discussão, sem que, aparentemente, tenha o objetivo de informar ou ensinar. Até porque Malraux defende a ideia de que o excesso de historicidade na verdade é um fator limitante da arte como objeto de reflexão.

Para Jean-Pierre Zarader (1998), na obra em que analisa o pensamento malruciano sobre arte, a reflexão sobre arte nos textos de Malraux vai bem além do historicismo, se mostrando sobretudo como uma filosofia da arte. Zarader (1998) afirma que, ainda que a história e a arte tenham sido as duas grandes paixões de Malraux, o escritor não reduz sua visão à mera história da arte, o que conduziria a uma análise limitada e mesmo conservadora da arte, como, assinala o teórico, era então tendência no século XX. Malraux não procura na história as respostas às questões que a arte pode colocar, embora não deixe de lado as considerações e os fatos históricos, o que é de se esperar. Aliás, o escritor procura defender a ideia da arte como criação autônoma de seu tempo, o que encontra eco em diversos filósofos, como Hegel. E, ao reunir, e confrontar, história e filosofia da arte, sem no entanto ser historiador ou mesmo filósofo, o pensamento de Malraux sobre arte mostra uma complexidade que vai além da que a história da arte costuma apresentar. Zarader (1998, p. 11) resume bem a questão: "A l'opposé de tout historicisme, Malraux n'a cessé de mettre en évidence le caractère énigmatique de la création - et son indépendance à l'égard de l'histoire. Véritable philosophie 
de l'art, son cuvre se distingue ainsi de toutes les histoires de l'art $\gg .^{3}$

Para Malraux, portanto, a arte não se resume à história. A visão de Zarader, autor que se notabilizou por sua obra crítica sobre a questão da arte em Malraux, poderia ser uma voz isolada, já que o ministro escritor dificilmente é reconhecido pelos teóricos como crítico, historiador ou filósofo da arte. Porém, a leitura de Zarader (1998) vai ao encontro não apenas dos textos mais familiares de Malraux sobre arte, mas pode ser uma referência também em seus discursos, nos quais é possível encontrar noções desenvolvidas em suas obras críticas, como vontade, antidestino e metamorfose, bem como uma preleção que envolve elementos históricos e filosóficos sobre a relação entre arte e sociedade. É interessante notar que, em trechos de diferentes discursos, ele discorre, de forma quase instrutiva, sobre questões de história da arte, sempre como uma forma de relacioná-las aos temas tratados e lembrando a importância dos museus e do patrimônio na intermediação entre arte e sociedade. No discurso Sur l'héritage culturel, de 1936, ele parece inaugurar o que poderia ser chamado de 'reflexões sobre arte' nos discursos, nos quais comenta sobre as diferentes formas de ver a arte ao longo dos tempos. Embora ainda distante do período em que atuou como ministro, Malraux (1996, p. 134) demonstra a importância da transmissão do patrimônio cultural e uma reflexão bastante atual sobre a recepção da arte:

Sous le mot art, nous envisageons deux activités assez différentes: l'une, que j'appellerai rhétorique - celle de l'artiste hellénistique, renaissant ou moderne - où l'oeuvre compte moins que l'artiste, compte pour ce que l'artiste ajoute à ce qu'il figure. L'autre - celle du Moyen Âge, de l'Égypte et de Babylone - où l'artiste compte moins que ce qu'il figure. Dans la première, l'importance est dans la présence de l'artiste; dans la seconde, dans la chose représentée. Ce

${ }^{3}$ Tradução minha do trecho em destaque: 'Opondo-se a todo historicismo, Malraux não cansou de pôr em evidência o caráter enigmática que reside em toda criação, bem como sua independência em relação à história. Verdadeira filosofia da arte, sua obra se distingue, assim, de todas as histórias da arte'. 
qui tient d'ordinaire à la valeur capitale donnée à cette chose représentée: comment se sentir artiste, au sens moderne du mot, en sculptant un crucifix, si l'on croit que le Christ est mort pour soi? La douleur de Niobé ne concerne qu'elle, et l'artiste s'y introduit sans peine; la douleur de la Vierge concerne tous les hommes. Quand le sculpteur antique doit paraître, le sculpteur chrétien doit disparaître ${ }^{4}$

Assim, Malraux (1996) afirma que a arte pode ser conhecida através de duas categorias diferentes: a arte retórica, característica do período helênico, renascentista e moderno, na qual o artista conta mais do que a obra; e a outra, referente à Idade Média, ao Egito e à Babilônia, na qual a obra de arte conta mais do que aquele que a cria. Dessa forma, Malraux (1996) põe em cena a discussão entre obra e artista, arte e religião, considerando que, quando a obra de arte consiste num instrumento de acesso ao divino, o significado do termo artista se apresenta diferente daquele que se coloca na modernidade, que propõe a importância da noção de autoria. Ao confrontar as duas formas de criação e percepção da obra de arte, ele apresenta a discussão sobre a arte como mediação tanto entre o homem e o sagrado, quanto entre o homem e a estética. Se, como afirma Malraux (1996), o que conta numa escultura de santo é o santo, mas o que conta num Cézanne é o Cézanne, a gradual saída do elemento religioso no ato de criação vai transformar a arte num objeto autônomo e independente de sua época. Ao desenvolver essa discussão, Malraux coloca em cena também os espaços e formas de transmissão dessa arte

\footnotetext{
${ }^{4}$ Tradução minha do trecho em destaque : 'Sob a palavra arte, compreendemos duas atividades diferentes : uma, que chamaria de retórica - a do artista helênico, renascentista ou moderno - na qual a obra conta menos do que o artista. A outra - da Idade Média, do Egito e da Babilônia - na qual o artista importa menos do que o que ele cria. Na primeira, a importância está na presença do artista; na segunda, na coisa representada, o que leva à questão sobre o valor dado a essa representação. Afinal, como se sentir artista, no senso moderno do termo, esculpindo um crucifixo, se acreditamos que Cristo morreu por nós? A dor de Niobé só diz respeito a ela, e o artista aí se interpõe sem problema; a dor da Virgem diz respeito a todos os homens. Quando o escultor antigo deve aparecer, o escultor cristão deve desaparecer.'
} 
que não mais é vista como manifestação do sagrado, mas como manifestação da grandeza humana. Ao pensar a arte como forma de acesso à possibilidade de grandeza existente no próprio homem, isto é, como meio de ter consciência dessa grandeza, entram no debate as formas de transmissão dessa história cultural. E, como ele ressalta, até as formas de transmissão e de apreensão (recepção) mudam de natureza e de forma, introduzindo o que mais tarde Malraux denominaria metamorfose da obra de arte. No discurso Sur l'héritage culturel, de 1936, a noção de metamorfose já se faz presente, ainda que o termo não seja utilizado na fala. Malraux (1996, p.136) também chama a atenção para o fato de que o homem procura na arte sua linguagem desconhecida, "o desconhecido" (l'inconnu). Ainda que o conceito de "desconhecido" não seja definido objetivamente por Malraux, o termo parece dialogar com o pensamento de Benjamin de que a crítica estética tem como função acessar o que há de misterioso e escondido na obra de arte.

Assim, a grande questão colocada por Malraux é que, ainda que a arte seja uma tradução do seu tempo, esse contexto histórico, por si só não dá conta de sua totalidade, isto é, pensar a obra de arte somente em sua historicidade é limitar as possibilidades de compreensão que ela oferece. Para ele, a obra surge do seu tempo e no seu tempo, mas se torna obra de arte pelo que ela não permite alcançar, "[..] par ce qui lui échappe" (MALRAUX, 1996, p.136) ${ }^{5}$. Como já foi dito, é nesse sentido que se insere o termo desconhecido, que aparece mais de uma vez em seus discursos, designando justamente essa dimensão do desconhecido, do inalcançável, presente na obra de arte.

Malraux afirma que a função da sociedade atual é permitir que o conhecimento dessa dignidade humana, manifesta através da arte, venha à tona, através da transmissão da herança cultural, com a consciência de que esse processo tem constantemente sua natureza modificada:

La photo de Rembrandt mène à Rembrandt, et la mauvaise peinture n'y mène pas.

${ }^{5}$ Tradução minha do trecho em destaque: '[...].pelo que lhe escapa.' 
Mais peu importe que nous nous en réjouissions ou nous en attristion: ce qui importe, c'est que ce fait nouveau est la condition même de la transmission de notre héritage culturel qui, par cette transmission même, change de nature.”(MALRAUX, 1996, p.136) ${ }^{6}$

As transformações no processo de recepção da obra de arte, ou na transmissão da herança cultural da humanidade, se devem ao desenvolvimento dos meios de difusão e da tecnologia que, como lembra o escritor, permite a acessibilidade das massas à arte, ainda que isso não signifique necessariamente algo positivo: "Or, l'art de masses est toujours un art de vérité. Peu à peu, les masses ont cessé d'aller à l'art, de le rencontrer au flanc des cathédrales; mais aujourd'hui, il se trouve que, si les masses ne vont pas à l'art, la fatalité des techniques fait que l'art va au masses" (MALRAUX, 1996, p.135)'.

No ensaio Malraux critique d'art, François de SaintChéron (2001) faz uma leitura interessante sobre a visão de Malraux como crítico de arte. Para ele, o escritor não é nem esteta nem historiador da arte - e, por isso, tampouco um "mau historiador da arte", como criticaram alguns - e se inscreve na tradição dos escritores e poetas que também foram autores de escritos sobre arte, como é o caso de Diderot, Baudelaire, Valéry e Proust (SAINT-CHÉRON, 2001). Além da notória influência das ideias de determinados pensadores, como Benjamin, Hegel

${ }^{6}$ Tradução minha do trecho em destaque : 'A foto de Rembrandt leva à Rembrandt, mas a pintura ruim não leva a nada. Pouco importa, na verdade, se gostamos ou não ; o que importa é que esse novo fato é a condição da transmissão de nosso patrimônio cultural que, por essa transmissão mesmo, muda de natureza.'

N. da T. Optei por traduzir a expressão «héritage culturel» por patrimônio cultural, em vez de herança cultural, por compreender que, apesar de os dois termos existirem na língua portuguesa, o primeiro é mais utilizado.

${ }^{7}$ Tradução minha do trecho em destaque : 'Ora, a arte das massas é sempre uma arte da verdade. Pouco a pouco, as massas pararam de ir até a arte, de encontrá-la nas catedrais; mas hoje, ocorre que, se as massas não vão até a arte, fatalmente as técnicas fazem a arte chegar às massas.' 
e Henri Focillon, Saint-Chéron ressalta que o texto malruciano se mostra essencialmente pessoal, amparado por um vasto e profundo conhecimento sobre arte e cultura. Seu projeto nunca foi de ordem histórica ou mesmo estética, mas sobretudo inserido numa metafísica, apoiado na ideia central de que, para Malraux (1996), a função da arte é dar consciência aos homens da grandeza que existe neles. Além disso, para falar sobre arte, Malraux havia escolhido o que Saint-Chéron (2001) chama de "língua poética", num tom celebrativo e lírico, como para suscitar no leitor/ouvinte a instantânea identificação com o mundo da arte:

Efetivamente, para celebrar o que escapa ao tempo - pois seus livros sobre arte são uma celebração-, Malraux escolheu uma língua poética capaz de suscitar, como por contágio (palavra que ele amava), a adesão do leitor e sua participação no mundo da arte. Podemos nos perguntar por que ele adotou esse tom oratório, poético e lírico para falar de arte. (SAINTCHÉRON, 2001, p.07)

Assim, verifica-se que essa 'metafísica da arte' é recorrente nos discursos de Malraux, e graças a ela é possível ver que, ainda que à primeira vista se aproxime de uma abordagem histórica, há uma recusa de uma concepção de um progresso linear na arte, mostrando muito mais uma problemática do que uma gradação evolutiva. São essas questões, pouco usuais em discursos políticos, que permitem considerar seu conjunto de falas como uma extensão de sua obra crítica sobre arte. Ou, ainda, ver a grandeza do pensamento malruciano que, ao fazer uso dos discursos políticos para construir um discurso estético, estabelecia um diálogo permanente com teóricos da arte como Benjamin, Adorno, Hegel e Schlegel, pondo em cena uma abordagem e uma apresentação peculiares das noções sobre arte, patrimônio e civilização.

\section{Malraux, o intelectual ambivalente}

O que é um intelectual engajado? Esta é uma questão que se apresenta da biografia à obra de Malraux. Não se trata de buscar 
uma definição fechada ou discutir o que é ser intelectual no sentido geral, já que todos aqueles que deixaram um legado escrito baseado em valores morais, e se comprometeram ideologicamente, podem ser apontados como tal. Mas pensar a reflexão de Malraux sobre cultura é pensar o intelectual que ele buscou ser e como esse papel, e seus valores morais, se refletiram em sua escrita, em sua fala, e em suas ações. $\mathrm{O}$ intelectual malruciano é interno e externo ao próprio autor; está presente em sua ficção, em sua reflexão e em sua ação. Portanto, investigar suas ideias e investigar Malraux como intelectual é situá-lo em um itinerário, numa problemática da qual ele faz parte. Interrogar-se sobre suas ideias é pôr em cena seus valores, suas recusas, seus projetos e seus compromissos. $\mathrm{Na}$ verdade, a expressão 'intelectual engajado' se mostra redundante, na medida em que se compreende o intelectual, por definição, como aquele que conectou suas ideias a um compromisso social e/ou político.

Inserir Malraux no grupo dos intelectuais, porém, é uma tarefa delicada que ultrapassa a dificuldade mesmo em definir o que é um intelectual. A figura de Malraux é tão complexa e ambivalente que ele não se coloca de acordo com qualquer definição, ainda que, paradoxalmente, também não esteja em desacordo. A tarefa do intelectual, de acordo com Edward W. Saïd (1996), é de manter à distância suas afinidades e afiliações ideológicas, bem como seu pertencimento nacional, para agir de maneira correta. $\mathrm{O}$ intelectual de Saïd é um exilado, um marginal, alguém que põe de lado seu sentimento de nacionalidade ou de ideologia para criticar com autenticidade e, assim, criar uma linguagem que fala ao poder (SAÏD, 1996, p.69). Saïd (1996) compara o intelectual a um náufrago, mas um náufrago como Marco Pólo, e não como Robinson Crusoé, que procura se adaptar ao novo destino. Marco Pólo, por sua vez, é um eterno viajante, guiado pelo sentido do maravilhoso:

Um intelectual se assemelha a um náufrago que, de certa maneira, aprende a viver com o país, e não no país. Não um Robinson Crusoé, cujo objetivo é de colonizar sua pequena ilha, mas sobretudo um Marco Pólo guiado pelo sentido do 
maravilhoso ; nem conquistador nem saqueador, mas eterno viajante e hóspede provisório. (SAÏD, 1996, p.76)

Malraux seria, portanto, uma mistura de Marco Pólo e de Robinson Crusoé, orientado pelo sentido do maravilhoso - as artes e a cultura, de uma forma geral -, viajante e sempre de passagem, mas também conquistador do mundo. Seu senso apurado pelas artes o guiou, até o fim de seus dias, a ser um flâneur do mundo; a olhar o outro com olhos de estrangeiro, mas um estrangeiro estranhamente familiar à diferença. Em francês, o termo 'estrangeiro' (étranger - século XIV) deriva de 'estranho' (étrange - século XI), que, por sua vez, deriva do latim 'extraneus' e significa 'de fora'; sendo estrangeiro, portanto, o que não é conhecido, o que não é familiar; de outra nação ou de outro país. $\mathrm{E}$, ao mesmo tempo, o que é fora do comum, extraordinário, singular. Assim, a etimologia do termo 'estrangeiro' remete a dois sentidos: ao mesmo tempo, ao que é de fora e/ou de outra nação, e ao que é singular ou bizarro, causando estranheza ${ }^{8}$. É interessante observar que Malraux se aproxima da dicotomia presente na essência da concepção de estrangeiro, como aquele que está sempre em deslocamento, a observar o mundo; e como aquele que é singular, estranho, de fora, causa estranheza e perplexidade; ele mesmo, às vezes, também confrontado à estranheza do outro, do mundo. Dessa forma, pode-se pensar justamente que a estranheza, em seu conjunto de significados, é o que melhor define a personalidade e a obra de Malraux, devido à própria estranheza que carrega em si, fazendo-o sempre o 'de fora', o estrangeiro, na acepção de Saïd; e o eterno questionamento, em suas reflexões, da estranheza da condição humana. Malraux (1996, p. 256, tradução nossa) comenta, em um discurso para a defesa do patrimônio histórico em Atenas, que a Grécia foi a primeira

${ }^{8}$ Informações de acordo com os verbetes 'étrange' e 'étranger' dos seguintes dicionários etimológicos da língua francesa: BAUMGARTNER, Emmanuèle, MÉNARD, Philippe. Dictionnaire etymologique et historique de la langue française. Paris: La Pochotèque, 1996 e DUBOIS, Jean; MITTERAND, Henri; DAUZAT, Albert. Dictionnaire etymologique. Paris: Larousse, 2001. 
a unir "a lança e o pensamento". 9 O binômio parece se refletir também no próprio orador, que personifica, de certa forma, esse ‘duelo' entre ação e reflexão, entre luta e pensamento, o que só mostra a complexidade em classificá-lo de acordo com categorias objetivas. Malraux não foi um filósofo propriamente dito; também não foi um crítico de arte tradicional; tampouco um acadêmico, ou um político. Escritor, sim; mas também, embora não seja uma oposição, foi um exímio orador, o que é um tanto incomum. Sua fala, cuidadosamente elaborada, acompanhava a torrente de seus pensamentos, e não havia distinção entre uma platéia burocrática, artística, intelectual ou popular. Na sua oralidade havia a presença de conceitos filosóficos, noções sobre cultura e patrimônio, elementos de história da arte; tudo formando um grande bouillon cultural, expressão usada pelo colaborador Pierre Moinot ao se referir à miscelânea complexa de ideias sempre presente nos mais diversos discursos. Janine Mossuz-Lavau (1982, p.149) comenta, em André Malraux et le gaullisme, que Malraux parecia considerar a política como um domínio a ser percorrido de acordo com seu ritmo e sua vontade; flanando aqui e ali, evitando o que o desinteressava, retomando certos lugares, e até inventando novos caminhos (MOSSUZ-LAVAU, 1982, p.149). A trajetória de Malraux foi marcada pela longevidade e pela multiplicidade de seus engajamentos políticos: Indochina, nos anos 20; Guerra da Espanha, nos anos 30; a Resistência Francesa, nos anos 40; a aproximação com De Gaulle e o futuro cargo político, nos anos 50/60; e, por fim, o envolvimento no conflito de independência do Bangladesh, em 1971. Para Dominique Villemot, em André Malraux et la politique, por essas características, o escritor se inscreve no grupo de intelectuais franceses para quem a ação política é um prolongamento natural da escrita, como Voltaire, Lamartine, VictorHugo, ÉmileZola, Gidee Sartre, para citaralguns. Porém, Malraux se diferencia destes justamente pela pluralidade de formas pelas quais manifestou seu comprometimento político, apresentando-se como intelectual engajado em seus escritos, combatente armado e ministro, o que o torna um exemplo único

${ }^{9}$ Tradução da expressão original: "La lance et la pense". 
na história da literatura francesa (VILLEMOT, 1996, p.151). Villemot (1996) utiliza o tom crítico para observar que, em certo sentido, Malraux foi um verdadeiro homem político, na medida em que, em determinadas situações, ele teve que suavizar suas convicções ideológicas a fim de atender a interesses políticos. Tal fato ocorreu em algumas ocasiões polêmicas, como a Guerra da Argélia, e questões de conflito relativas a obras cinematográficas (o desgaste por conta da censura do filme $A$ religiosa e do caso da Cinemateca Francesa). Para Villemot (1996, p. 149), a política de Malraux foi pautada na ação, e não na razão.

No grupo de escritores franceses que, nos séculos XIX e XX, se envolveram em querelas políticas, se inserem grandes nomes: Zola, Victor Hugo, Georges Sand, Sartre, Gide, Camus. O grande caso modelo considerado por historiadores é o Caso Dreyfus (1897), no qual o célebre texto J'accuse, de Zola, deu a abertura ao que seria uma das maiores e mais polêmicas histórias políticas da França. O Caso Dreyfus reuniu, em posições às vezes conflitantes, um expressivo número de escritores, desde o abaixo-assinado de apoio ao ex-militar condenado por traição, até discussões e rompimentos acalorados. É considerado pela historiografia francesa o caso modelo de definição dos limites do que seria o tipo ideal de intelectual e do anti-intelectual, por assim dizer. Sua importância reside no fato de ser considerado como o momento em que intelectuais assumem seu papel enquanto homens críticos e livres pensadores, ao se posicionarem política e publicamente.

No que se refere a escritores que também foram homens políticos, podem ser lembrados Chateaubriand, Maurice Barrès, Lamartine, Léon Blum, além do próprio Malraux. Herbert Lottman, em sua obra L'écrivain engagé et ses ambivalences, propõe uma forma de diferenciar os homens políticos que se tornaram escritores e os escritores que se tornaram políticos, ainda que todos possam ser chamados de intelectuais engajados: para ele, o escritor engajado se apóia numa obra já expressiva e que, de certa forma, expressa sua concepção de mundo e suas ideias, a 
serviço de uma causa. Isto é, a reputação precede o engajamento e lhe confere mais valor. ${ }^{10}$

Maxime Blanchard (2008, p.11), no texto S'engager: l'intellectuel dans l'oeuvre d'André Malraux, enfatiza o lado intelectual presente nas ficções malrucianas, afirmando que mesmo em suas narrativas o engajamento político se põe em cena, através da ação e da reflexão de seus protagonistas. Dessa forma, seu discurso ficcional corrobora o pensamento e a ação do próprio autor.

Mas mesmo essa regra tem suas ambigüidades; criação e ação às vezes se encontram em pontos comuns de uma dada trajetória. Como na de Chateaubriand, por exemplo, em que as duas funções se misturaram desde o início. No caso de Malraux, já ministro, ele escreve Si Delacroix - il y a cent ans, em 1960, como prefácio da obra Sumer de André Parrot, no qual ele retoma suas ideias sobre arte e civilização já apresentadas em $L a$ métamophose des dieux e Les voix du silence. Como ministro, ele continua a desenvolver sua reflexão sobre arte, reeditando $L e$ musée imaginaire no ano de 1965, em texto revisto e ampliado ${ }^{11}$, e publicando ainda Antimémoires (1967). A publicação de Antimémoires dá início a uma série de entrevistas de Malraux e de reportagens sobre ele, nas quais a mídia destaca "o retorno [de Malraux] à coisa escrita" ". Como afirma Blanchard (2008), ação e escrita estão intrinsecamente conectadas na obra deste escritor que mostra que a crítica e a responsabilidade são os dois lados da mesma moeda para quem sempre buscou se posicionar de maneira

${ }^{10} \mathrm{O}$ atual Ministro da Cultura e da Comunicação da França, Frédéric Miterrand, também possui uma obra literária realizada antes de se tornar ministro, mas seus textos se destacam sobretudo por conta de elementos autobiográficos polêmicos que lhe valeram acusações públicas durante seu mandato.

${ }^{11}$ Le musée imaginaire já havia sido publicado em 1947 e 1951 (na segunda data, como primeira parte de Les voix du silence). Ref CHANUSSOT e TRAVI, Dits et écrits d'André Malraux. 2003, p. 356.

12 « Un entretien exclusif avec Michel Droit. Malraux parle... »Le Figaro Littéraire, n.1120, oct. 1967. Ref CHANUSSOT e TRAVI, 2003, p. 374. Tradução minha do original: "le retour [de Malraux] à la chose écrite". 
firme em relação às próprias escolhas ideológicas, embora isso não signifique que não tenha se envolvido em contradições e polêmicas. A intelectualidade de Malraux é externa e interna à sua escrita, e se coloca sob a forma da responsabilidade, da ação política e da crítica de arte. Na verdade, mostra-se mesmo complicado separar arte e política sob o ponto de vista da biografia de Malraux; e, em certa medida, o mesmo pode ser dito de sua obra ficcional, se pensarmos em determinados contextos históricos utilizados em algumas narrativas, como La tentation de l'Occident, La Voie Royale e Antimémoires.

Para Michel Déguy (2006), no ensaio "O poder das palavras", a função do intelectual pode ser resumida da seguinte forma: fazer a triagem do senso comum, isto é, discernir para separar ou conjugar; comparar para aproximar ou afastar. Ele observa que os intelectuais fazem da palavra - linguagem, discurso - sua arma de poder sobre os homens, a fim de mudar convicções, objetivos e maneiras de agir. Por isso, a retórica por muito tempo foi chamada de a arte de persuadir. Dessa forma, coloca (2006), o poder é sempre poder das palavras, e ter o poder, na esfera do político, significa ser obedecido:

Ter o poder (entendido agora como questão e esfera do político) consiste, em ultima análise, em ser obedecido. [...] Eis porque a eloqüência, de Demóstenes a Lênin, de Cícero a Zola ou Jaurès, sempre foi admirada, analisada, cultivada, como um dos ingredientes fundamentais da tomada do poder e da manutenção do poder. (DÉGUY, 2006, p.211).

Déguy (2006) continua, e discorre sobre dois tipos ou figuras, ao mesmo tempo arcaicos e modernos, pois se tornam uma constante na história, e que representam o poder das palavras: um é o conselheiro do príncipe, sábio ou louco; o outro, o intelectual, no sentido de ser advogado ou defensor de uma causa capaz de envolver multidões. O primeiro age em segredo, a sós com o grande chefe, dirigindo-se apenas a ele; o outro se dirige para a coletividade, a multidão. Essas duas modalidades então apresentam, simultaneamente, a relação entre política e 
intelectual, no sentido de alguém que domina as palavras a fim de persuadir. Para o teórico, o poder das palavras sustentaria o que, no século $\mathrm{XX}$, foi chamado de engajamento, pois o intelectual engajado tinha como pressuposto a capacidade da persuasão. Déguy (2006) então cita Sartre como exemplo da intelectualidade engajada, mas lembrando, com fino sarcasmo, que ele também havia se enganado, ainda que conseguisse, apesar de seus enganos, ser bastante ouvido. O fato é que Sartre, adversário do regime gaullista, se enganou justamente ao criticar Malraux. Ao afirmar, durante viagem ao Brasil nos anos 60, que "a cultura não tem necessidade de ministério", Sartre não pôde antever o quanto cultura e política se entrelaçariam ainda mais, dando início ao que Déguy chama de "o cultural", expressão já citada anteriormente. Para Déguy (2006), na época estava tendo início a era do cultural, em que a cultura - o cultural - e a política, na forma do ministério, seriam uma coisa só a serviço da economia, da arte e da cultura: "Sartre não viu - mas como poderia ter visto? - que entrávamos na era do cultural e que a cultura, agora cultural (o cultural), e a política, isto é, o ministério, seriam uma coisa só a serviço de uma economia dita geral de consumo, absorvendo e arrastando a arte e a cultura" (DÉGUY, 2006, p.212). Ele prossegue, afirmando que Malraux foi o inventor do cultural e do pré-cultural, ao propor uma relação entre arte, cultura e política.

Assim, é interessante utilizar o pensamento de Deguy (2006) e mesmo o tom de crítica em relação a Malraux, a fim de pensar que a ambivalência de seu papel político-intelectual se mostra, muitas vezes, reduzido à dicotomia entre arte e política, ou entre poesia e política. Para usar os termos de Déguy a tradição histórica mostra que as figuras do homem político e do poeta são incompatíveis e que foi esse debate, de certa forma, que levou à revolução de 68, com a defesa da "imaginação do poder". Malraux, como inventor do pré-cultural, encarnava o papel do poeta que, ousadamente, também se queria político. Além disso, como nas figuras arquetípicas lembradas por Déguy (2006), Malraux não era nem o conselheiro do rei nem o advogado das multidões: ele era os dois ao mesmo tempo. Braço direito de De Gaulle quanto às 
questões relativas à cultura, bem como maestro da coletividade, ele era em si mesmo o paradoxo sublime, para utilizar expressão de Déguy, em busca de uma democracia esclarecida ${ }^{13}$.

Ainda que, para Déguy, já não exista mais a arena, no sentido de recinto político destinado à realização de discursos, comícios, manifestações, etc., tendo esta sido substituída pela mídia, Malraux ainda é, em essência, um homem de arena, um homem de ágora. Além da sua conhecida aptidão para a oratória e, conseqüentemente, o domínio da multidão, era também notória sua reduzida eficácia quando se pronunciava através da mídia, através de, por exemplo, transmissões televisivas ou reproduções sonoras. Malraux marcaria, portanto, a passagem não somente da era do engajamento para a do testemunho, e da cultura para $o$ cultural, como também da arena para a mídia. Outro fato a ser comentado é que, em seus discursos, por vezes, a distância entre ministro e artista se vê bastante reduzida graças à forma utilizada pelo escritor de se posicionar, o que só mostra que, afinal, Déguy (2006) estava certo ao afirmar que poesia - compreendida aqui em sua essência literária - e política são incompatíveis e que esse duplo posicionamento de Malraux deixou-o, posteriormente, sem saída. Esta é uma das questões mais interessantes ao se abordar os discursos de Malraux de maneira analítica: percebe-se que, como enunciador, Malraux procura se aproximar de sua platéia, formada predominantemente por artistas e pessoas ligadas à cultura, ainda que eventualmente tenha falado para platéias burocráticas - caso dos discursos na Assembléia Nacional - ou generalizadas. Ao se colocar, portanto, mais como artista/poeta do que como político, ele quebra o protocolo ministerial e, de certa forma, cria empatia e identificação com o público não afeito à política, mas à cultura.

\section{Arte e cultura como interrogação do mundo}

A discussão sobre arte que atravessa toda a obra de André Malraux, desde seus discursos até seus textos sobre estética, se

${ }^{13}$ A expressão «democracia esclarecida » também é de Déguy, numa junção das noções de oligarquia, de Rancière, e de despotismo esclarecido. 
fundamenta no que Jean-Pierre Zarader chama de "valorização da arte". Essa valorização da arte se refere sobretudo à dimensão metafísica que a arte pode apresentar; tal pensamento pode ser visto em determinadas afirmações suas, que colocam a arte como antidestino, e a arte como expressão da mais profunda liberdade, assim como a cultura: "Ainsi, art et culture nous apparaissent-ils comme l'expression de la plus profonde liberté" (MALRAUX, 1996, p.219). ${ }^{14}$ A reflexão estética nos discursos malrucianos apresenta a tendência de investigar a arte e a cultura como instrumentos que conduzem o homem, individual e coletivamente, ao questionamento da condição humana. Assim, as noções de cultura e, de forma mais específica, de arte se confundem com outras noções, como metamorfose e vontade. Quando Malraux opõe às declarações " $C$ 'est toujours la mort qui gagne" e «C'est toujours la métamorphose qui gagne» $\square$, ele apresenta sua visão de uma arte que se mostra como única via de desafiar a morte. E é nesse sentido que se desenvolve, ao longo de seus discursos, a discussão sobre cultura e arte. Daniel Castillo Durante, em seu breve ensaio, se refere ao discurso de Malraux como sendo um 'discurso humanista', cuja função seria se mostrar "um farol intelectual para o Ocidente" (DURANTE, 1994, 1995, p.137). Ele lembra, no entanto, que a mundialização dos mercados e a globalização do conceito de cultura resultaram em uma perda para os discursos humanistas. Atualmente, o conceito de cultura atravessou diversas mudanças, implicando novas noções e relações, como o próprio campo de Estudos Culturais: indústria cultural, redes digitais e globalização.

Assim, a era da informação se mostra como uma característica da contemporaneidade, apresentando novas noções que interferem na questão cultural, e mesmo nas relações entre arte, cultura e comunicação, implicando também o surgimento de outras formas de criação e de expressão, como blogs, fotografias e livros digitais. Porém, embora não se descarte a importância

${ }^{14}$ Tradução minha do trecho em destaque : 'Assim, arte e cultura nos aparecem como expressão da mais profunda liberdade.' 
de uma análise conceitual à luz da atualidade, trata-se aqui de mostrar que, em Malraux (1996, p.226), as noções de arte e cultura foram construídas a partir de uma reflexão sobre a própria função do homem no mundo: "Notre culture est une interrogation orientée par la volonté d'accroître la conscience de l'homme." (MALRAUX, 1996, 226) ${ }^{15}$. E, dessa forma, são noções que ultrapassam o tempo, assim como a obra de arte se eterniza através da metamorfose.

No discurso realizado no Palais Bourbon, em 1963, Malraux (1996, p.226) afirma que a cultura pode ser compreendida como o que, na vida, escapa ao domínio da morte: "La culture, c'est ce qui dans la mort est tout de même la vie [...]" "16. A declaração vai ao encontro do pensamento que está presente constantemente em suas alocuções, como na que foi pronunciada em evento da Unesco pela defesa do patrimônio egípcio: "[la culture] c'est l'acte par lequel l'homme arrache quelque chose à la mort" (MALRAUX, 1996, p.266) ${ }^{17}$.

Assim, observa-se que, para o escritor, a cultura é a possibilidade de integrar o homem através do tempo, seja o que já passou seja aquele por vir, através das questões que se colocam no momento de sua própria existência:

Une culture, c'est d'abord l'attitude fondamentale d'un peuple en face de l'univers. Mais ici, aujourd'hui, ce mot a deux significations différentes, et d'ailleurs complémentaires. D'une part, nous parlons du patrimoine artistique de l'Afrique; d'autre part, nous parlons de sa création vivante. Donc, d'une part, nous parlons d'un passé; d'autre part, d'un avenir. (MALRAUX, 1996, p.331) $)^{18}$

\footnotetext{
${ }^{15}$ Tradução minha do trecho em destaque : 'Nossa cultura é uma interrogação orientada pela vontade de aumentar a consciência do homem.'

${ }^{16}$ Tradução minha do trecho em destaque : 'A cultura é aquilo que, na morte, ainda assim pertence à vida'. MALRAUX, Discours au Palais Bourbon (1963). Centre des Archives Nationales, Site Fontainebleau, Cote 2009, p.131, art. 195. ${ }^{17}$ Tradução minha do trecho em destaque : '[A cultura] é o ato pelo qual o homem arrebata algo da morte.'

${ }^{18}$ Tradução minha do trecho em destaque : 'Uma cultura é, primeiramente,
} 
O passado é retomado; mas não mais como um passado intacto e intransferível, e sim metamorfoseado pelo diálogo com as outras obras de arte e pelo olhar do presente. Se a arte é a única coisa capaz de fazer o homem fugir à morte, os museus oferecem possibilidades de referências e de interações:

Bien entendu, c'est le passé. Mais non, comme naguère, un passé élu: un passé modèle. Parce que la culture comprend désormais tout le passé. À l'imaginaire qui déferle sur toutes les cités dressées dans le monde par la civilisation industrielle, répondent la découverte et l'admiration du passé de la terre entière. Jamais les peintres n'avaient admiré tant de formes de tant de civilisations; mais ce qu'ils ont trouvé dans tant de musées, ce ne sont pas de plus nombreux asservissements, c'est la plus profonde liberté. (MALRAUX, 1996, p.292) ${ }^{19}$

A discussão em torno da reprodutibilidade da obra de arte é recorrente tanto em sua obra crítica quanto em seus discursos. A partir do século XIX, a civilização industrial e os meios de difusão característicos da modernidade possibilitaram o acesso a obras de arte e ao patrimônio de um passado até então conhecido por um pequeno e privilegiado grupo. Para Malraux (1996), a interação com o passado é realizada através de escolhas que se referem, sobretudo, às obras que despertam e determinam a consciência da grandeza do próprio homem. Assim como a cultura, o passado, como herança, não é transmitido, mas conquistado:

a atitude fundamental de um povo frente ao universo. Mas aqui, hoje, essa palavra tem dois significados diferentes e, também, complementares. Por um lado, falamos do patrimônio artístico da África; por outro lado, falamos de sua criação vívida. Então, por um lado, falamos de um passado ; por outro lado, de um futuro.'

${ }^{19}$ Tradução minha do trecho em destaque : 'Claro, é o passado. Mas não, como antes, um passado eleito, um passado modelo. Porque a cultura compreende a princípio todo o passado. Ao imaginário devastado pela civililização industrial, respondem a descoberta e a admiração da terra inteira. Nunca antes os pintores admiraram tantas formas de tantas civilizações. Mas o que eles acharam nos museus não foram numerosos exemplos de submissões, mas da mais profunda liberdade.' 
Toute civilisation est en cela semblable à la Renaissance et fait son propre héritage de tout ce qui, dans le passé, lui permet de se dépasser. L'héritage ne se transmet pas, il se conquiert. Mais il se conquiert lentement, imprévisiblement. $\mathrm{Ne}$ demandons pas plus à une civilisation sur commande que des chefs- d'oeuvre sur commande. Mais demandons à chacun de nous de prendre conscience que le choix qu'il fait dans le passé - dans ce qui fut l'espoir illimité des hommes - est à la mesure de son avidité de grandeur et de sa volonté. (MALRAUX, 1996, p.142) ${ }^{20}$

No entanto, ainda que Malraux sempre busque, de alguma forma, uma definição da ideia de cultura - e, convém ressaltar, uma concepção de cultura que não se refere à abordagem antropológica - é preciso observar que a tarefa não é simples, como ele mesmo reconhece, numa fala em Nova York, em 1962, pouco antes do lendário empréstimo de La Joconde aos Estados Unidos. Para o ministro escritor, embora a cultura, sob a forma de cultural na acepção de Déguy, tenha se desenvolvido imensamente no que se refere à difusão do conhecimento, ao crescimento do público interessado, e mesmo à consciência da importância de haver uma política de governo que se dedique à questão cultural, com a criação de ministérios específicos, ainda assim o termo cultura coloca sua complexidade em ser definido:

Une réunion comme celle-ci eût été inimaginable il y a cinquante ans. Depuis un an, les entrées aux expositions de peinture sont plus nombreuses que les entrées dans les stades; les villes d'art sont devenues ce qu'étaient jadis les villes de pélerinage; les gouvernements, l'un après l'autre - en Union Soviétique comme aux Etats-Unis - créent ou développent des

${ }^{20}$ Tradução minha do trecho em destaque : 'Toda civilização é, nesse aspecto, igual à do Renascimento e faz seu próprio patrimônio de tudo que, pertendendo ao passado, ainda assim o ultrapassa. O patrimônio não é transmitido, mas conquistado. Mas conquistado lentamente, imprevisivelmente. Não devemos mais encomendar obras de arte, mas tomar consciência de que a escolha feita no passado - naquilo que foi a esperança ilimitada dos homens - tem a mesma medida de sua avidez de grandeza e de sua vontade.' 
ministères des Affaires Culturelles. Mais l'idée de culture est devenue d'autant plus obsédante, qu'on est moins appliqué à la définir. (MALRAUX, 1996, p.287). ${ }^{21}$

$\mathrm{Na}$ verdade, ao propor suas definições, Malraux admite a complexidade de determinar, de maneira fechada, noções e respostas em relação à cultura. Dessa forma, ele procura sobretudo apresentar suas ideias sobre a função da arte e da cultura na sociedade, como uma busca de resposta do homem para suas interrogações, em vez de propor definições objetivas e limitadas. Se a própria noção de cultura é difícil de ser mensurada, controlada, definida, é justamente nesse sentido que se insere o pensamento malruciano, a fim de mostrar que cultura e arte põem em cena um mistério, no âmbito conceitual e estrutural, e que se houvesse uma ideia capaz de abarcar as diversas possibilidades oferecidas pelos dois campos, dando conta de suas indefinições e pluralidades, seria justamente a da interrogação, a do ser-nãosendo; isto é, pensar a cultura e a arte como formas da interrogação em si mesma e da interrogação da relação entre homem e mundo. Talvez esta seja a forma mais honesta de propor uma definição - ou não-definição - dos dois termos. O que não impede, naturalmente, a importância de pensar a cultura e, conseqüentemente, a arte, refletindo sobre sua função na humanidade. Isto posto, parece-me que é justamente essa segunda abordagem, a função da cultura e da arte, que se mostra mais freqüente e expressiva no discurso malruciano, e não exatamente definições completas dos termos. $\mathrm{Na}$ incompletude das noções reside justamente sua dimensão misteriosa, que permite às manifestações e às obras de arte constantemente se transformarem, se eternizarem.

${ }^{21}$ Tradução minha do trecho em destaque : 'Uma reunião como essa seria inimaginável há cinquenta anos. Há um ano as idas às exposições de pintura são mais numerosas do que as idas aos estádios; os lugares consagrados às artes se tornaram o que antes eram os centros de peregrinagem; os governos, um após o outro, tanto na União Soviética como nos Estados Unidos, criam ou desenvolvem ministérios da cultura. Mas quanto mais a idéia de cultura se torna obssessiva, mais diculdade temos em defini-la.' 
Em La monnaie de l'absolu, Malraux afirma que nossa civilização se diferencia das anteriores - com exceção da Grécia - pela importância que ela reconhece à interrogação. Assim, se as ciências fazem dessa interrogação justamente seu fundamento, "Notre art, lui aussi, devient une interrogation du monde." (MALRAUX, 1951, p.601)22 A Grécia, como ele observa no discurso de homenagem ao país, em 1959, constitui a primeira civilização sem livro sagrado para quem a inteligência significou questionamento (MALRAUX, 1996, p.256). A referência à civilização grega está presente também em Benjamin (BENJAMIN, 1996, p.175), que aborda a questão ao falar sobre valores de eternidade. Segundo ele, por conhecerem apenas dois processos técnicos para a reprodução da obra de arte, o molde e a cunhagem, que eram utilizados somente nas moedas e nas terracotas, os gregos construíam obras únicas e para a eternidade. $\mathrm{E}$, conseqüentemente, foram obrigados a produzir valores eternos. Assim, tanto para Malraux quanto para Benjamin, a arte deveria conter em si uma dimensão de eternidade, talvez através de sua esfera aurática, que ultrapassa a dimensão de tempo ou mesmo de espaço (com o museu, por exemplo), fundamentado em valores, em inteligência, em espírito, e não mais numa estética pura - arte pela arte - ou tampouco a arte como expressão do sagrado.

Para André Malraux (1996), a cultura não se define como uma forma de refinamento ou um repertório de conhecimentos, ainda que certos conhecimentos sejam intrínsecos a ela, como, por exemplo, o elemento histórico que busca dar sentido ao passado. De fato, Malraux ilustra através de sua obra a premissa de que a cultura permeia, com maior ou menor intensidade, a mediação entre o mundo sensível e o real; ou seja, ela é a diferença possível dentro do cotidiano de cada indivíduo. $\mathrm{O}$ escritor busca confrontar uma possível noção de cultura à própria história da arte, mostrando que, sob a perspectiva histórica, a arte e a cultura se mostram relacionadas à questão religiosa, na medida em que,

${ }^{22}$ Tradução minha do trecho em destaque: 'Nossa arte também se torna uma interrogação do mundo.' 
num primeiro momento da história da arte, muito do que era criação humana era feito como acesso ao divino, portando em si uma dimensão do sagrado. É isso que ele procura abordar no discurso do I Festival Mundial de Artes Negras, em Dakar, no qual proferiu a alocução de abertura. Ao se direcionar ao público africano, ele procura discutir as diferenças que permeiam a arte sagrada e a arte cuja função já nasce estética, questão que está presente sobretudo no universo cultural da África:

La vérité est qu'un art, magique ou sacré, se crée dans un univers dont l'artiste n'est pas maître. Lorsque le monde sacré disparaît, il ne reste de ce qu'il fait qu'une obscure communion ou une sympathie [...]. Mais, pour le sculpteur de Chartres, ces statues qu'on appelait les Rois et qui sont des saints, on les priait, on ne les admirait pas; et pour les Africains qui sculptaient des masques, ces masques se référaient à une vérité religieuse et non à une qualité esthétique. (MALRAUX, 1996, p.334). ${ }^{23}$

Para Malraux, tudo parte da constatação de que a cultura, ou sobretudo uma consciência da cultura, substituiu a alma pelo espírito, e a religião pelo pensamento científico, tornando a busca de um significado pela vida de acordo então com as leis dos homens, e não mais com as leis divinas : "Elle [la nouvelle civilisation] a remplacé l'âme par l'esprit, et la religion non pas par la métaphysique, mais par la pensée scientifique, la signification de la vie par les lois du monde." (MALRAUX, 1996, p.321). ${ }^{24}$ Conseqüentemente, a arte, como esfera da cultura

${ }^{23}$ Tradução minha do trecho em destaque: ‘A verdade é que uma arte, mágica ou sagrada, se cria num universo em que o artista não é o mestre. Assim que o mundo sagrado desaparece, só resta dele uma obscura comunhão ou uma simpatia [...]. Mas, para o escultor de Chartres, essas estátuas conhecidas como Reis são, na realidade, santos. Nós orávamos por eles, mas não os admirávamos. E, para os africanos que esculpiam máscaras, essas máscaras se referiam a uma verdade religiosa e não a uma qualidade estética.'

${ }^{24}$ Tradução minha do trecho em destaque : 'Ela [a nova civilização] substituiu a alma pelo espírito, e a religião, não pela metafísica, mas pelo pensamento científico, e o significado da vida pelas leis do mundo'. 
e expressão humana, acompanha essa nova concepção de mundo posta pela cultura. Assim, à medida que o sagrado e a religião são substituídos pela esfera estética relacionada à obra de arte, isso não impede que o objeto carregue em si uma proposta de comunhão, ainda que essa comunhão como fator de união e ligação entre os homens não se dê mais pelo aspecto religioso. Para Malraux, a arte não se tornou uma religião, mas implica uma espécie de fé, ao resgatar as obras de arte e o patrimônio de uma dimensão temporal, da mesma maneira que a crença religiosa resgatava do tempo manifestações religiosas, como a estatuária sagrada, as máscaras e os rituais. Ao templo sagrado e à igreja, se sucede o museu. Malraux acredita que a função do museu é similar a dos lugares consagrados ao sagrado, e ele mostra, como exemplo, o Louvre e sua relação com as grandes obras de arte da humanidade, como Van Gogh e Matisse. Para ele, os museus também eternizam a arte ao retirarem dela sua função original, seja sagrada, utilitária ou decorativa:

L'art n'est évidemment pas devenu religion, mais il est devenu foi. Le sacré de la peinture n'est plus un sacré des Dieux, c'est un sacré des morts. Pour Cézanne comme pour Van Gogh, Degas, Matisse ou Braque, le lieu sacré, c'est le Louvre. Parce que pour chaque peintre, les oeuvres qu'il y élit sont survivantes. Ses images délivrées du temps étaient souvent nées pour des lieux délivrés du temps: l'église, le temple. A sa manière, le musée aussi est délivré du temps. $\left(\right.$ MALRAUX, 1974, p. 230) ${ }^{25}$

É interessante pensar que o trecho acima foi retirado de seu discurso na Fondation Maeght, em 1973, por ocasião da exposição consagrada a ele e ao museu imaginário. Assim, justamente ao

${ }^{25}$ Tradução minha do trecho em destaque: 'A arte evidentemente não se tornou religião, mas se tornou fé. O sagrado da pintura não é mais um sagrado dos Deuses, mas um sagrado dos mortos. Tanto para Cézanne quanto para Van Gogh, Degas, Matisse ou Braque, lugar sagrado é o Louvre. Porque, para o pintor, as obras que ali estão como eleitas são sobreviventes. Essas imagens à margem do tempo nasciam para lugares também à margem do tempo: a igreja, o templo. À sua maneira, o museu também é à margem do tempo.' 
afirmar os museus como lugares do "sagrado", no sentido de espaço que resgata as obras de arte, tornando-as sobreviventes ao tempo, para utilizar sua própria expressão, Malraux deixa de lado a concepção tradicional de museu como lugar de memória, ou um guardião do passado, conservador e estático no tempo. Ao contrário, o museu malruciano tem uma predisposição ao movimento, à renovação, à metamorfose.

O discurso Occidentaux, quelles valeurs défendez-vous?, realizado em 1952 no Congrès pour la liberté de la culture, anos antes de Malraux se tornar Ministro, já expunha o amadurecimento intelectual do escritor ao discutir a noção de cultura e definindo-a como o "L’héritage de la noblesse do monde" (MALRAUX, 1996, p.217). ${ }^{26}$ Assim, a cultura tem função crítica, na medida em que leva o indivíduo a pôr em questão os próprios limites da condição humana. Daí a importância da arte e da memória histórica como formas de consciência de um passado direcionado para o presente e o futuro, ainda que construído sobre a noção do trágico. A cultura, então, dá forma à arte e à metamorfose da própria história, que se reinventa através da memória projetada pelo olhar do presente. É justamente essa possibilidade infinita de recriação permitida pela arte que torna o homem menos escravo de seu próprio destino, isto é, menos preso à sua condição:

$\mathrm{O}$ que ela [a cultura] deve conquistar para criar um tipo de homem exemplar e dar forma a seu novo passado é a presença, em si mesma, de todas as formas de arte, de amor, de grandeza e de pensamento que, no decurso dos milênios, permitiram sucessivamente ao homem ser cada vez menos escravo [...](MALRAUX, 1998, p.39).

Nota-se que a concepção de cultura como forma de tornar o homem menos escravo é de certa forma frequente em seus discursos, como se pode ver no mesmo Occidentaux, quelles valeurs défendez-vous?: "La culture est l'ensemble de toutes les formes d'art, d'amour et de pensée qui, au cour des millénaires,

${ }^{26}$ Tradução minha do trecho em destaque : 'legado da nobreza do mundo'. 
ont permis à l'homme être moins esclave." (MALRAUX, 1996, p.218) ${ }^{27}$. Por menos escravo, pode-se compreender como o conhecimento das formas de arte e de pensamento permite ao homem se sobrepor, ao menos metafisicamente, à condição humana. Esse tema da arte como interrogação do mundo e da condição do próprio homem é constante na reflexão estética de Malraux, mostrando uma abordagem quase metafísica do termo. Na verdade, é possível perceber um questionamento do próprio Malraux, através da arte e da cultura, da estranheza e da confusão causadas pela condição que é inerente ao homem; a constatação da morte, sem nunca negá-la, ou mesmo contestá-la, parece ser o grande questionamento do escritor. Assim, as formas encontradas pelo homem - e por ele mesmo - de enfrentar esse destino inevitável se dão através da literatura, da arte e da cultura, pois dessa maneira o homem tenta transformar em inteligível o que não é compreensível à própria razão. Ele afirma então que o homem não nasce da própria afirmação, mas da interrogação do universo, numa tentativa de se sobrepor ao mundo efêmero (MALRAUX, 1996, p.135).

Pode-se afirmar que, de certa maneira, Malraux antecipa questões e projeções que teriam destaque apenas no final do século XX e no início do XXI, como o impacto dos meios de informação e de reprodução nas obras de arte:

Depuis trente ans, chaque art a inventé son imprimerie: radio, cinéma, photographie. Le destin de l'art va du chef d'oeuvre unique, irremplaçable, souillé par sa reproduction, non seulement au chef-d'oeuvre reproduit, mais à l'oeuvre faite pour sa reproduction à tel point que son original n'existe plus: le film.(MALRAUX, apud SUARÈS, 1974, p.47). ${ }^{28}$

${ }^{27}$ Tradução minha do trecho em destaque: 'A cultura é o conjunto de todas as formas de arte, de amor e de pensamento que, ao longo dos milênios, permitiram ao homem ser menos escravo.'

${ }^{28}$ Tradução minha do trecho em destaque: 'Há trinta anos, cada tipo de arte inventou seu modo de impressão : rádio, cinema, fotografia. $\mathrm{O}$ destino da arte vai da obra de arte única, insubstituível, manchado por sua reprodução, à obra de arte reproduzida e, ainda, à reprodução da reprodução, de tal forma que o 
Ainda em seu discurso no Ministério da Educação e da Cultura, o escritor pondera que a criação artística é a única maneira de se sobrepor ao destino, pois evoca o que existe de inatingível na existência humana: "O objeto da cultura torna-se então muito diferente daquilo que se julgava ser: torna-se a busca, e, se possível, a descoberta do elemento invulnerável do homem e daquilo em que o homem pode fundamentar sua grandeza". Interessante notar que, ainda que Malraux procure relacionar as noções de arte e de cultura ao desaparecimento, ou enfraquecimento, da presença da religião como mediadora da relação entre homem e mundo, no discurso malruciano a reflexão sobre arte e cultura está sempre conectada à ideia do divino, mesmo que não mais sob uma forma religiosa. Percebe-se isso claramente quando, por exemplo, no discurso Sur l'héritage culturel, de 1936, Malraux (1996, p.160) afirma que toda arte é uma lição dos deuses:

Tout art est une leçon par ses dieux. Car l'homem crée ses dieux avec tout lui-même, mais il crée son art le plus haut avec le monde réduit à l'image de son secret toujours le même: faire éclater la condition humaine par des moyens humains. Nous avons fait un certain nombre d'images qui valent qu'on en parle, non seulement dans les arts, mais dans l'immense domaine de ce que l'homme tire de lui-même pour s'accuser, se nier, se grandir ou tenter de s'éterniser. (MALRAUX, 1996, 160) ${ }^{29}$

O conceito de vontade também se faz presente na obra malruciana. De acordo com o escritor, a vontade é a grandeza que guia os homens, a despeito da diversidade de suas escolhas, em direção a valores como liberdade e comunhão. $\mathrm{O}$ mundo secular

original não existe mais, como é o caso do filme.'

29 Tradução minha do trecho em destaque : 'Toda arte é uma lição por seus deuses. Pois o homem cria seus deuses através dele mesmo, mas cria sua arte através do mundo reduzido à imagem de seu segredo, que é sempre o mesmo : expressar a condição humana através de meios humanos. Fizemos numerosas imagens das quais vale a pena falar, não só no âmbito das artes, mas também no imenso campo daquilo que o homem tira de si mesmo para se acusar, se negar, crescer ou tentar se eternizar.' 
só tem significado a partir da vontade dos homens, e é justamente esse preceito que os orienta e os une, apesar das diferenças ideológicas. Ele afirma que os homens devem estar à altura de seus sonhos, e são esses sonhos que fornecem a dignidade da existência. Nesse sentido, observa-se em seus discursos a noção recorrente de um apelo à união dos homens através da arte: a arte como mediação, como meio de ascensão e possibilidade de escapar ao destino. Somente a obra de arte sobrevive ao tempo e se inscreve na pedra da história; e, sendo a arte maior que a própria tragédia, ela preservará a magnificência do homem. Malraux cita, a título de exemplo, o legado do império assírio, cuja obra-símbolo tornou-se uma referência memorialística mais significativa do que a violência de sua história, tornando-se parte do Patrimônio Cultural da Humanidade: "O império mais sangrento do mundo, o império assírio, deixa em nossa memória a majestade de sua Leoa ferida: se existe uma arte dos campos de extermínio, ela não representará os carrascos, representará os mártires" (MALRAUX, 1998, p.39). Portanto, para ele a obra de arte sempre representará e preservará o melhor do espírito humano. $\mathrm{E}$, nesse aspecto, parece que a reflexão malruciana caminha num sentido quase paradoxal. Se, por um lado, Malraux contrapõe a cultura à religião, a alma ao espírito, a crença à inteligência, ele invariavelmente recorre às noções semânticas da própria religião, no que diz respeito ao sagrado, ao divino, à igreja. Para Malraux, ainda que a função suprema da arte e da cultura seja permitir que o homem interrogue o próprio destino e o mundo que o envolve, ambas partilham de esferas comuns com a religião, seja através de uma comunhão alcançada por valores, seja porque a cultura, na concepção malruciana, é o que permite ao homem ter consciência simultaneamente de suas duas partes, o que não significa uma cisão: sua natureza humana, estranha, confusa; e sua parte divina, consciente da dimensão que pode alcançar através da criação artística. Aqui, não se trata então de uma criação de mundo, mas de uma re-criação do mundo, segundo as leis humanas. 


\section{REFERÊNCIAS}

BAUDELAIRE, Charles. Sobre a modernidade. São Paulo: Paz e Terra, 2007.

BECQ, Annie. Le XVIIIe siècle a-t-il invente la critique d'art? Critique et champ artistique en quête d'autonomie em France de 1699 à 1791. In: FRANGNE , Pierre-Henry Frangne; POINSOT, Jean-Marc Poinsot (Dir.) L'INVENTION de la critique d'art. Rennes: PUR, 2002.

BENJAMIN, Walter. A obra de arte na era da reprodutibilidade técnica. In: . Obras escolhidas I. São Paulo: Brasiliense, 1996.

BLANCHARD, Maxime. S'engager: l'intellectuel dans l'œuvre d'André Malraux. Arras: Artois Presses Universitaires, 2008.

CHANUSSOT, Jacques ; TRAVI, Claude. Dits et écrits d'André Malraux. Dijon: Universitaires de Dijon, 2003. Collection Écritures.

DÉGUY, Michel. Du culturel dans l'art. In: LA raison poétique. Paris: Galilée, 2000.

. O poder das palavras. In: NOVAES, Adauto (org.). O silêncio dos intelectuais. São Paulo, Companhia das Letras: 2006.

DURANTE, Daniel. Le concept de culture chez André Malraux à l'aube du nouveau millénium. Revue André Malraux Review. v. 25, n.1/2, 1994/1995.

JIMENEZ, Marc. Qu'est-ce que l'esthétique? Paris: Gallimard, 1997.

MALRAUX, André. Les Voix du silence : Le Musée imaginaire, La Création artistique - La Monnaie de l'absolu. Paris: Gallimard, 1951.

. La Tête d'obsidienne. Paris: Gallimard, 1974.

. Le Musée Imaginaire. Paris: Gallimard, 2006.

. Discours au Brésil: Palavras no Brasil. Organização de Edson Rosa da Silva. Rio de Janeiro: Funarte, 1998. (Discursos)

. La Politique, la culture. Paris: Gallimard, 1996. (Discursos)

. Discours au Palais Bourbon (1963). Centre des 
Archives Nationales, Site Fontainebleau, Cote 20090131, art. 195. (Documento manuscrito)

MOSSUZ-LAVAU, Jeanine. André Malraux et le gaullisme. Paris : Presses des Sciences, 1982.

POULOT, Dominique. Museu, nação, acervo In: BITTENCOURT, José Neves et al. In: História representada: o dilema dos museus. Rio de Janeiro: Museu Histórico Nacional, 2003.

SAÏD, Edward W. Des intellectuels et du pouvoir. Paris: Seuil, 1996. SAINT-CHÉRON, François. Malraux critique d'art. Communication proposée au Colloque Centenaire de la naissance d'André Malraux, Université Silpakorn, Bangkok, 27-28 nov., 2001. Disponível em: $<$ http://www.malraux.org/index.php/articles/909-fsc1.html $>$. Acesso em 12 jan. 2010.

SUARÈS, Guy. Malraux, celui qui vient: entretiens entre André Malraux, Guy Suarès, José Bergamin. Paris: Éditions Stock, 1979.

VILLEMOT, Dominique. André Malraux et le politique: l'être et l'histoire. Paris: L'Harmattan, 1996.

ZARADER, Jean-Pierre. Le vocabulaire de Malraux. Paris: Ellipses: 2001.

. Malraux ou la pensée de l'art. Paris: Ellipses, 1998.

Recebido em 27/03/2013.

Aprovado em 17/10/2013. 